\title{
Invasive Species Population Status Modeling Using Stage Based Matrix: Mount Elgon Ecosystem
}

\author{
S. O. Ojung'a, J. O. Nyakinda, E. Okuto, J. A. Mullah
}

\begin{abstract}
The matrix models have been applied to evaluate the impacts and management of tree species. Modeling of invasive species using stage based matrix methods has not been exploited to understand the population structure of the invasive species. The study simulated using stage-structured Lefkovitch models to assess the population structure and impacts of invasive population growth within Mount Elgon Ecosystem. The survey data were used to calculate the transition probabilities and the growth rate (Kiptogot $\lambda 1=1.074$ and Kimothon $\lambda 2=1.115$ and Saboti $\lambda 3=1.118$ ) in different forest blocks. These results indicate that Cestrum aurantiacum is increasing in population and could have effects on the population of other native species within ecosystems in the future.
\end{abstract}

Keywords-Matrix models, population, invasive species, degradation factors.

DOI: $10.7176 / \mathrm{MTM} / 9-2-04$

\section{INTRODUCTION}

$I^{1}$ NVASIVE species threaten global biodiversity, ecosystem structure and functioning [14], [22], [15]; consequently, invasion by non-native plants has caused tremendous economic losses worldwide. The alien plant invasions of protected areas are increasing worldwide and are widely recognized by managers as a major threat [17], [9]. According to Arim et al. [1], the invasive species has affected $60 \%$ of all species listed in the U.S. Endangered Species Act (1). Thus, in order to better understand the systems of biological invasion, investigation into the underlying mechanisms of invasion is crucial to ecological research and conservation planning. These species are major drivers of climate change, leading to biodiversity loss that is to be addressed by the Sustainable Development Goals (SDG) target 15.3 which specifically addresses land degradation. The invasive species has estimated a huge loss of up to USD 137.2 billion dollars per year in USA alone [21] and USD 248 billion worldwide [7]. The damages and destructions caused by invasive species has resulted into increased level of poverty which has slowed down economic growth and development among the developing countries since they rely most on agricultural activities for their livelihoods and growth [14], [7]. These damages and destruction globally cost about US\$1.4 trillion per year which is about 5\% of total world GDP. Hence the need study and understand the population structure of invasive plants [4], [23] and the factors that support for their growth.

S.O. Ojung'a is with the Kenya Forestry Research Institute, P.O Box 5199 Kisumu 40108 and with the Jaramogi Oginga Odinga University of Science and Technology, Kenya (Corresponding author; e-mail: mcojijosamsa@gmail.com).

\section{MATHEMATICAL BACKGROUND}

Mathematical modeling provides insight into problems by establishing mathematical relationships among the variables and parameters [12] that affect the population of species of flora and fauna. In 1895 the scientist named Cannan started the theory of prediction of life history of species population [6]. The matrix models were first developed by Bernardelli [2], Lewis [13], and Leslie [11]. Matrix model that classified the population based on the stage of life was modified by Lefkovitch and it is a modification of Leslie matrix where the classification were replaced by life stage [4]. The Lefkovitch matrix entries consists the rate of reproduction, survival, and growth in each class [3]. The first row of the projection matrix contains stage specific fertilities $\boldsymbol{F} \boldsymbol{i}$. The fertility $(\boldsymbol{F} \boldsymbol{i}>0)$ is the number of offspring of stage age $i$ to $(i+1)$ in a unit of time $t$ that will survive to the next stage class at time $(t+1)$.

The $\mathbf{S i}$ which is the survival rate $(0<\boldsymbol{S i}>1)$ is the probability that an individual of stage $i$ at time $t$ will survive to time $(t+1)$, when her stage will be $(\mathrm{i}+1)$ which is probability of surviving and remaining in the same stage given by:

$$
\operatorname{Si}=\delta_{i}\left(1-\gamma_{i}\right)
$$

where $\delta_{i}$ is the survival probability of stage $\mathrm{i}$ and $\gamma_{\mathrm{i}}$ the probability that a surviving individual grows from stage $i$ to stage (i+1)

$\boldsymbol{G} \boldsymbol{i}=$ Chances of surviving and moving from $\mathrm{i}^{\text {th }}$ stage to $(\mathrm{i}+1)$ stage given by [20]:

$$
G i=\delta_{i} \gamma_{i}
$$

Caswell [5] treated the density as a sum of all individuals in the population, setting up a matrix model with a population partitioned into $\boldsymbol{w}$ stage classes.

\section{MATERIALS AND METHODS}

The Cestrum aurantiacum flowers after two years and produces flowers for several months through summer and autumn. The plants are long-lived, producing new growth in spring. The Cestrum aurantiacum seeds are always dormant in the soil for some period of time. It is a shrub which generally grows 1-3 m high. Cestrum is a shrub of the Solanaceae family

J.O. Nyakinda and E. Okuto are with the Jaramogi Oginga Odinga University of Science and Technology.

J.A. Mullah is with the Kenya Forestry Research Institute, P.O Box 5199 Kisumu 40108. 
that is a toxic plant and has become an invasive weed. It prefers moist habitats but is commonly found along roadsides, and neglected, disturbed, and abandoned sites [8].

To build a mathematical model that simulate the population size and structure of invasive species of Cestrum aurantiacum in $\mathrm{Mt}$ Elgon of Kenya, we classified the ecosystem into forest zones where we had nested experimental plots used for assessing the invasive species over a period of one year. Three transect $(1 \mathrm{~km})$ were done per sub-blocks per forest block, where data was collected within adjacent nested plots $300 \mathrm{~m}$ apart. Invasive species plants in each plot were recorded and grouped into stages namely trees, sapling and seedlings for analysis and modeling.

\subsection{Model description and construction}

The Lefkovitch matrix population model [11]; allows classification of the population by stage classes. The model advances a given population structure through one-time interval to a new projected population structure. Through time interval, reproduction and survival occur within each stage class in the population at rates specific to each stage class. Thus, the survival probabilities and reproductive rates of each stage class contribute to a new population structure at time $(t+1)$ from time $t$. Under this model, changes in population structure are denoted by the equation 3 given below:

$$
\mathbf{n}(\mathbf{t}+\mathbf{1})=\mathrm{A} \mathbf{n}(\mathbf{t})
$$

Where $\boldsymbol{n}$ represents a vector of stage class population structure at times $(t+1)$ and $t$, respectively.

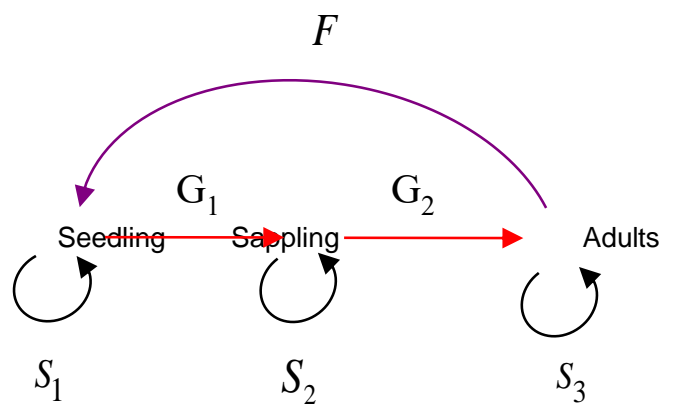

The model stage based matrix (A) model is given below

$\mathrm{A}=\left[\begin{array}{ccc}S_{11} & 0 & F \\ G_{12} & S_{22} & 0 \\ 0 & G_{23} & S_{33}\end{array}\right]$

The basic form of the matrix models that consider environmental variabilities with vital rates corresponding to environments are given by the non-negative matrices $\boldsymbol{A}_{\boldsymbol{\delta}} \in$ $R^{N X N}, \delta=1, . . S$ in such a way that, for each $\delta, A_{\delta}$ represents the vital rates of the population in environment $\boldsymbol{\delta}$. The environmental variation is characterized by a sequence of random variables $\boldsymbol{\tau}_{\boldsymbol{t}}, \boldsymbol{t}=\mathbf{0}, \mathbf{1}, 2, \ldots$. defined in a certain probability space $(\Omega, \boldsymbol{\varphi}, \boldsymbol{p})$ and with state space $1, \ldots s$. For each $\boldsymbol{\varphi} \in \boldsymbol{\omega}$ of the process, the population of the species is subjected to environmental conditions $\tau_{\omega}$ during times $\mathbf{t}$ and $(\mathbf{t}+\mathbf{1})$. In this way, the model reads:

$Z_{t+1}=A \quad \tau_{t+1} Z_{t}$

where for each $\boldsymbol{t}=\boldsymbol{0}, 1, \ldots, \boldsymbol{Z}_{t}$ is a vector random variable in $\boldsymbol{R}^{N}$ which represents the population vector at time $n$ and assume that $\boldsymbol{Z}_{\boldsymbol{0}}$ is a fixed non-zero vector $\boldsymbol{Z}_{\boldsymbol{0}} \geq \boldsymbol{0}$ [4]. The stage based model is shown by a life-cycle interaction and/or transition among the stages.

\subsection{Model parameter estimation}

The population projection matrix A contains the survival probabilities and reproductive rates acting on the population through each time interval. Where $\boldsymbol{A}$ is the density-dependent population projection matrix and we assume temporally homogeneous environment per ecological and forest block site. The elements of the square matrix $\boldsymbol{A}$ are non-negative, the elements of the first row are greater than or equal to zero, the elements of its main sub-diagonal are positive and less than unity and the remaining elements are zero. The dominant eigenvalue of the population projection matrix, denoted by lambda, is the growth rate of the population. If lambda $=1$, there is no change in the population size but if lambda $>1$ then the population is increasing while values of lambda $<1$ mean that the population is decreasing. The computation of the entries of matrix (A) are given Table 1 below:

Table 1: Model Parameters computation methods

\begin{tabular}{|c|c|c|c|}
\hline $\begin{array}{l}\text { Paramet } \\
\text { er }\end{array}$ & $\begin{array}{l}\text { Notatio } \\
\text { n }\end{array}$ & Meaning & $\begin{array}{l}\text { Computation } \\
\text { method }\end{array}$ \\
\hline $\begin{array}{l}\text { Fertility } \\
\text { rate }\end{array}$ & $\begin{array}{l}F i(F i \\
>0)\end{array}$ & $\begin{array}{l}\text { The rates } \\
\text { which is the } \\
\text { number of } \\
\text { offspring of } \\
\text { stage age } i \\
\text { to }(i+1) \text { in } \\
\text { a unit of } \\
\text { time } t \text { that } \\
\text { will survive } \\
\text { to the next } \\
\text { stage class } \\
\text { at time }(t+1) \\
\text { [20] }\end{array}$ & $\begin{array}{l}\text { Reproductive } \\
\text { Contribution. } \\
\qquad F_{i}=b(i) P_{i} \\
\text { Where b(i) = the } \\
\text { fecundity rate and } \\
\text { Si= the probability } \\
\text { of surviving to the } \\
\text { adult stage. The } \\
\text { value was } \\
\text { estimated using the } \\
\text { total number of } \\
\text { added seedling } \\
\text { sampled within the }\end{array}$ \\
\hline
\end{tabular}




\begin{tabular}{|c|c|c|c|}
\hline & & & $\begin{array}{l}\text { period of survey } \\
{[20]}\end{array}$ \\
\hline $\begin{array}{l}\text { Survival } \\
\text { rate }\end{array}$ & $\begin{array}{l}(0<S i \\
>1)\end{array}$ & $\begin{array}{l}\text { which is the } \\
\text { probability } \\
\text { that an } \\
\text { individual of } \\
\text { stage } i \text { at } \\
\text { time } t \text { will } \\
\text { survive to } \\
\text { time }(t+1) \text {, } \\
\text { and remain } \\
\text { in the same } \\
\text { stage }\end{array}$ & $\begin{array}{l}\left(\boldsymbol{S i}=\delta_{i}\left(1-\gamma_{i}\right)\right) \\
\text { Where } \delta_{i} \text { is the } \\
\text { survival } \\
\text { probability of stage } \\
\mathrm{i} \text { and } \gamma_{i} \text { the } \\
\text { probability that a } \\
\text { surviving } \\
\text { individual grows } \\
\text { from stage } \mathrm{i} \text { to } \\
\text { stage (i+1). } \\
\text { Estimated from } \\
\text { the data }\end{array}$ \\
\hline $\begin{array}{l}\text { Transitio } \\
n \text { rate }\end{array}$ & Gi & $\begin{array}{l}\text { the } \\
\text { probability } \\
\text { of surviving } \\
\text { and growing } \\
\text { from stage i } \\
\text { to stage } \\
(\boldsymbol{i}+1) \text { given } \\
\text { by [20] }\end{array}$ & $\begin{array}{l}\left(G i=\delta_{i} \gamma_{i}\right) \\
\text { The value was } \\
\text { estimated from the } \\
\text { data assuming the } \\
\text { rate of death per } \\
\text { stage is a ninth of } \\
\text { the survival rate }\end{array}$ \\
\hline $\begin{array}{l}\text { Eigen } \\
\text { value }\end{array}$ & $(\lambda)$ & $\begin{array}{l}\text { Long term } \\
\text { population } \\
\text { growth rate }\end{array}$ & $\operatorname{det}(A-\lambda I)=0$ \\
\hline $\begin{array}{l}\text { Eigen } \\
\text { vectors }\end{array}$ & $\mathbf{v}$ & $\begin{array}{l}\text { Long term } \\
\text { population } \\
\text { structure } \\
\text { correspondi } \\
\text { ng to } \\
\text { specific } \\
\text { eigenvalues }\end{array}$ & $\begin{array}{l}\text { Once the } \\
\text { eigenvalues of a } \\
\text { matrix ( } A \text { ) have } \\
\text { been found, we can } \\
\text { find the } \\
\text { Eigenvectors by } \\
\text { Gaussian } \\
\text { Elimination }\end{array}$ \\
\hline
\end{tabular}

\section{Results and Discussion}

\subsection{Projection Matrices}

The analysis of the growth rate and the elasticity has indicated that the predisposing factors (high temperature, low rainfall (mm), over-grazing, cutting down of trees, charcoal production and agricultural activities) cause significant population increase of Cestrum aurantiacum. The estimates presented here are point estimates, which will need confidence limits. In the subsequent analysis we will also investigate the possibility of using different levels predisposing factors of degradation for fertility and survival. The following table 2 outline the model parameters calculated.
Table 2: Model parameters of invasive species (Cestrum aurantiacum)

\begin{tabular}{|c|c|c|c|c|c|c|}
\hline $\begin{array}{l}\text { Forest } \\
\text { block }\end{array}$ & $\begin{array}{l}\text { Surviv } \\
\text { al per } \\
\text { stage }\end{array}$ & (Sii) & $(\mathbf{G i j})$ & $\begin{array}{l}\text { Mean } \\
\text { Popul } \\
\text { ation }\end{array}$ & $\begin{array}{c}\text { Eigen } \\
\text { value } \\
\lambda\end{array}$ & $\begin{array}{l}\text { Eigen } \\
\text { vector }\end{array}$ \\
\hline \multicolumn{7}{|c|}{ Kimothon } \\
\hline \multirow{2}{*}{ Stage 1} & 0.7625 & 0.084 & 0.7821 & \multirow[b]{4}{*}{248} & \multirow{6}{*}{2.94} & \multirow{6}{*}{$\begin{array}{l}(0.96,0.2 \\
6,0.11)\end{array}$} \\
\hline & 59 & 729 & 03 & & & \\
\hline \multirow{2}{*}{ Stage 2} & 0.8692 & 0.096 & $\begin{array}{l}0.7189 \\
\end{array}$ & & & \\
\hline & 03 & 578 & 43 & & & \\
\hline \multirow{2}{*}{ Stage 3} & 0.8141 & 0.090 & 0.6784 & 248 & & \\
\hline & 33 & 459 & 81 & \multirow[t]{2}{*}{148} & & \\
\hline \multicolumn{6}{|l|}{ Saboti } & \\
\hline Stage 1 & $\begin{array}{r}0.8829 \\
48\end{array}$ & $\begin{array}{r}0.098 \\
105\end{array}$ & $\begin{array}{r}0.7225 \\
81\end{array}$ & 315 & \multirow{4}{*}{3.14} & \multirow{4}{*}{$\begin{array}{l}(0.96,0.2 \\
8,0.10)\end{array}$} \\
\hline \multirow{2}{*}{ Stage 2} & 0.8157 & 0.090 & 0.7293 & \multirow{2}{*}{313} & & \\
\hline & 73 & 641 & 02 & & & \\
\hline Stage 3 & $\begin{array}{r}0.8701 \\
43\end{array}$ & $\begin{array}{r}0.096 \\
683\end{array}$ & 0.672 & 142 & & \\
\hline \multicolumn{7}{|c|}{ Kiptogot } \\
\hline \multirow{2}{*}{ Stage 1} & 0.7888 & 0.087 & 0.6954 & \multirow{2}{*}{666} & \multirow{5}{*}{3.49} & \multirow{5}{*}{$\begin{array}{l}(0.97,0.2 \\
3,0.07)\end{array}$} \\
\hline & 22 & 647 & 95 & & & \\
\hline \multirow{2}{*}{ Stage 2} & 0.8557 & 0.095 & 0.7157 & \multirow{2}{*}{329} & & \\
\hline & 83 & 087 & 89 & & & \\
\hline Stage 3 & $\begin{array}{r}0.7743 \\
39\end{array}$ & $\begin{array}{r}0.086 \\
038\end{array}$ & 0.768 & 225 & & \\
\hline
\end{tabular}

The following are the stage based population modeling matrix for the different forest block

$$
\begin{aligned}
A_{\text {Kiptogot }} & =\left[\begin{array}{ccc}
0.088 & 0 & 46 \\
0.789 & 0.095 & 0 \\
0 & 0.856 & 0.806
\end{array}\right], \\
A_{\text {Kimothon }} & =\left[\begin{array}{ccc}
0.0966 & 0 & 26 \\
0.763 & 0.085 & 0 \\
0 & 0.869 & 0.814
\end{array}\right], \\
A_{\text {Saboti }}= & {\left[\begin{array}{ccc}
0.099 & 0 & 29 \\
0.883 & 0.098 & 0 \\
0 & 0.816 & 0.870
\end{array}\right], }
\end{aligned}
$$




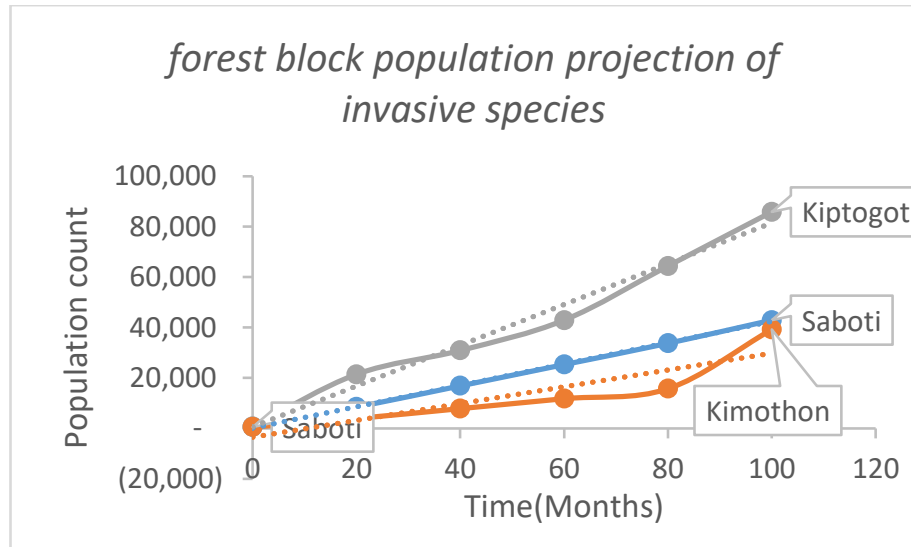

Figure 1: Forest block population projection of Cestrum aurantiacum

The above figure 1 shows the average count of seedlings, sapling and adult Cestrum aurantiacum per sampled plots per forest block. The results indicates a higher mean count in Kiptogot block than other forest blocks mainly because of the forest block is more disturbed that the other two blocks. The block is as a result of destruction and degradation [24]. The forests in this areas has been modified considerably over the years by human activities especially through urbanization, deforestation and intensive agricultural practices. The continued human activities within these forest blocks has put pressure on land for food production which have caused forest resources degradation [10].

\subsection{Growth rates of the population of invasive species per block}

The projection of the population per forest blocks are indicated in the graphs below and the extrapolated population in months.

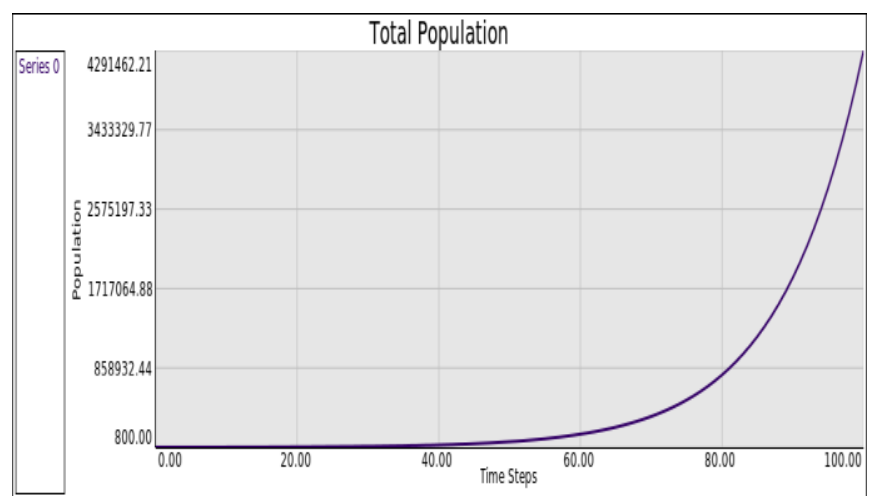

Figure2: Kiptogot forest block population projection of invasive species

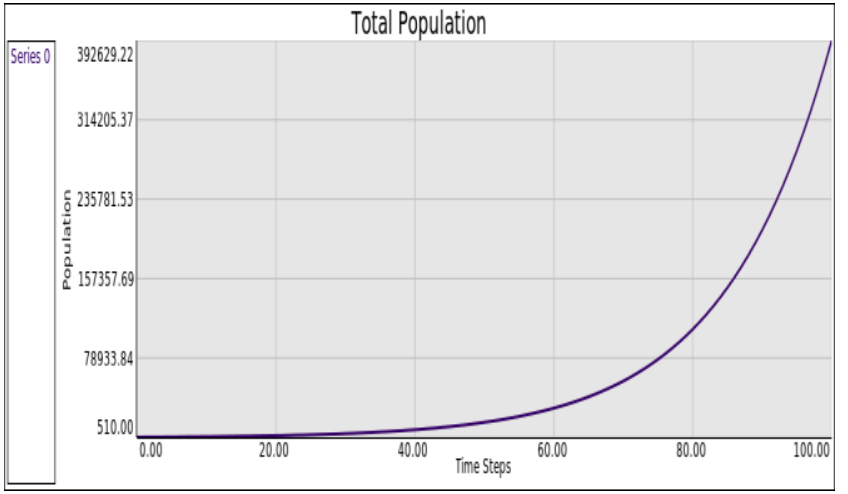

Figure 3: Kimothon forest block population projection of invasive species

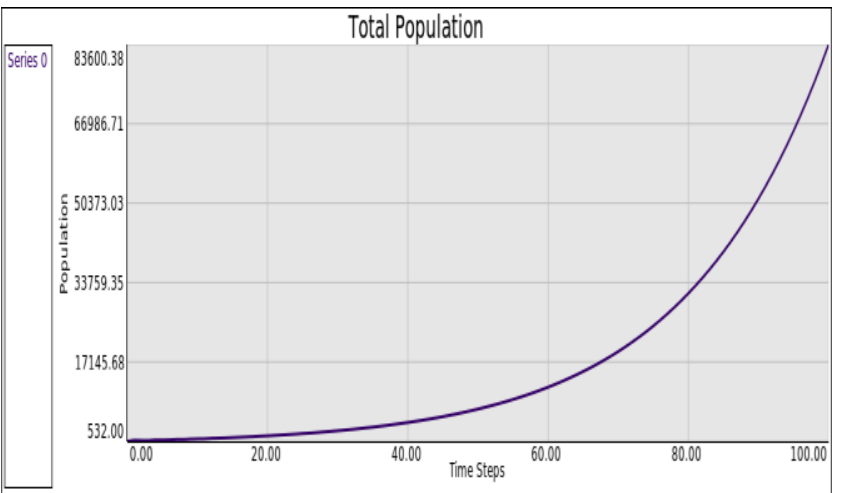

Figure 4: Saboti forest block population projection of invasive species

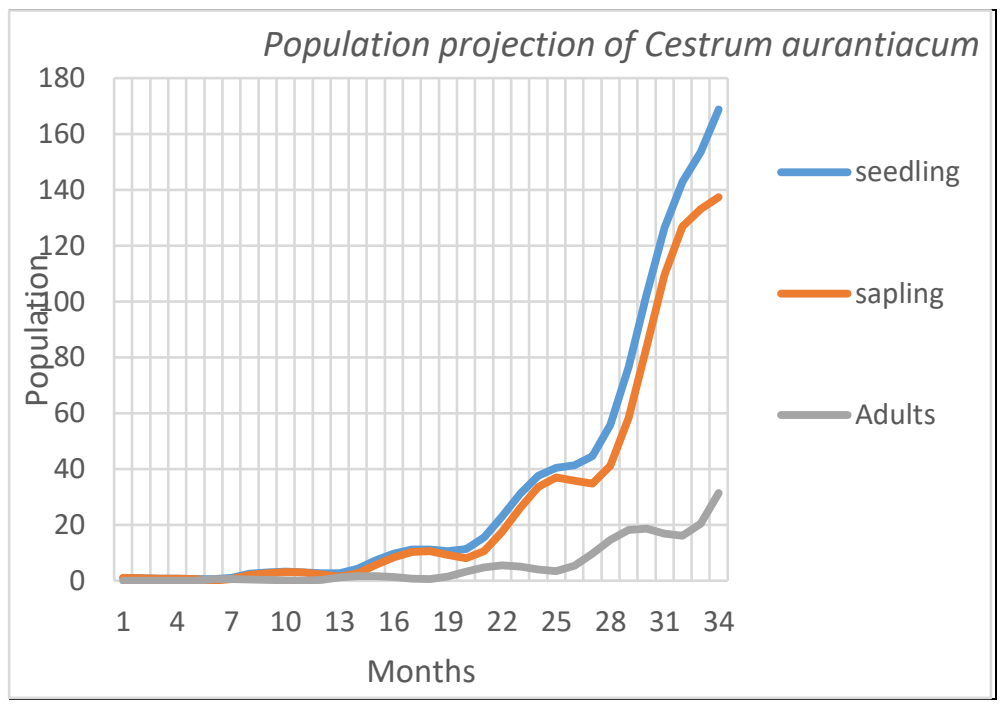

Figure 5: Population projection of Cestrum aurantiacum per stage in mt Elgon

The figure 5 indicates an increase in the population of both the seedlings, saplings and adult plants, hence need for population 
management within all the forest blocks. The results are consistent with results of Paul et.al [24] results that identified various degraded sites in Mt. Elgon ecosystems were within the forest reserves (closed natural forest, forest plantation, open natural forest and shrub land) and private farms. The main cause of degradation within the forest was over-grazing of livestock, illegal harvesting for timber and charcoal production and agriculture (where forest land was illegally acquired for farming and settlement) [24].

\subsection{Impacts of Cestrum aurantiacum on Mt Elgon and adjacent landscape}

There are at least two major adverse effects of the existence of an invasive species in a native ecosystem. First, invasive plant change native ecosystem processes such as nutrient or hydrology cycles and contribute to the decrease of native species abundance [15] [2] [18]. Second, C.aurantiacum is toxic to animal like sheep and goats [19] and possibly may have a similar effect on human [16] within the area. The main concern on the effect of increase of $C$. aurantiacum population as invasive species is by invading remnant forest ecosystem within Mt Elgon water towers and potentially invading the forest adjacent farm lands which are agriculturally productive and are the food basket of the western region of Kenya. Lastly, these native forest maintain ecosystem services which includes the hydrological balance and provide habitat and food for native animals hence a major threat by increase of $C$. aurantiacum.

\subsection{Conclusion}

The results from this preliminary study shows that Cestrum aurantiacum negatively impact on the indigenous plant species. However, to estimate the magnitude of the impact we need to incorporate more environmental factors which might play role in the invasion. Further studies could also include delineating the effects of different levels of degradation factors and investigate the variation in the effects on the population growth per stage of growth.

\section{References}

[1]Arim M., Sebastián Abades R., Paula Neill E., Mauricio L., Pablo Marquet A. (2006) Spread dynamics of invasive species; Proceedings of the National Academy of Sciences Jan 2006, 103 (2) 374-378; DOI: 10.1073/pnas.0504272102

[2]Bernardelli H. (1941) Population waves, J. Burma Research Society 31 (1941) pp 1-18.

[3] Bruce M. and Shernock E. (2002) Stage Based Population Projection Matrices and Their-Biological Applications December 13, 2002

[4] Caswell H. (2001). Matrix population models: construction, analysis and interpretation. 2nd edn. Sunderland, MA, USA, Sinauer. pp722.

[5] Caswell H.(2010), Reproductive value, the stable stage distribution, and the sensitivity of the population growth rate to changes in vital rates demographic research volume 23 , article
19, pages 531-548 published 07 September 2010 http://www.demographic-research.org/Volumes/Vol23/19/ DOI: 10.4054/Dem-Res.2010.23.19

[6] Cannan E. (1895) The probability of a cessation of the growth of population in England and Wales during the next century", Economic Journal 20 (1895) pp 505-515

[7] Cox G.W. (2004) Alien Species and Evolution .Washington, DC: Island Press. Google Scholar

[8] Global Invasive Species Database (2018) Species profile: Cestrum parqui. Downloaded from http://www.iucngisd.org/gisd/species.php?sc=850 on 14-022018.

[9] Foxcroft L.C., Pysek P., Richardson D.M., Genovesi P. MacFadyen S. (2017). Plant invasion science in protected areas: progress and priorities. Biological Invasions. doi: 10.1007/s10530-016-1367-z

[10] Gordon Ojwang O., Agatsiva J. and Situma C. (2010) Analysis of Climate Change and Variability Risks in the Smallholder Sector, Case studies of the Laikipia and Narok Districts representing major agro cological zones, Department of Resource Surveys and Remote Sensing (DRSRS) in collaboration with the Food and Agriculture Organization of the United Nations, Rome, 2010, FAO.

[11] Leslie P.H. (1945) On the use of matrices in certain population mathematics", Biometrika 33 (1945) pp 183-212.

[12] Leslie P. H. (1948) Some further notes on the use of matrices in population mathematics, Biometrika, 35:pp 213245

[13] Lewis. E.G. (1942) On the generation and growth of a population", Sankhya: The Indian Journal of Statistics 6 (1942) pp 93-96.

[14] Levine J.M, Vila M. D.and Antonio C.M. (2003), Mechanisms underlying the impacts of exotic plant invasions. Proc R Soc Lond B Biol Sci 270:77581.

[15] Mack R.N., Simberloff D., Lonsdale W.M. et al (2000) Biotic invasions: causes, epidemiology, global consequences, and control .Ecol Appl 10:689710

[16] McLennan, M.W. and W.R. Kelly. (1984). Cestrum parqui (green cestrum) poisoning in cattle. Australian Veterinary Journal 61: pp 289-291.

[17]Michael P., Kyle,Tomlinson W., Alice Hughes C. and Richard Corlett T. (2017) Alien plant invasions of protected areas in Java, Indonesia,www.nature.com/scientificreports/ [18] Mullah, C. J. A., Klanderud K., Totland Ø. and Odee D. (2014). Community invasibility and invasion by exotic Fraxinus pennsyvanica trees in a degraded tropical forest, Kenya. Biological Invasions 16:2747-2755.

[19] Mullah, C.J.A. (2012). Status of Cestrum invasion in Cherangany Forest Ecosystem. Report Compiled for KFS. KEFRI

[20] Musick J.A. \& Bonfil R. (2005) Management techniques for elasmobranch fisheries FAO, Rome, 2005 FAO Fisheries technical paper pp 474

[21] Pimentel D., Zuniga R., Morrison D., (2005) Update on the environmental and economic costs associated with alien invasive species in the United States. Ecol Econ 52:27388. 
[22]Richardson D.M., Pysek P., Rejmnek M. et. Al. (2000) Naturalization and invasion of alien plants: concepts and definitions .Divers Distributions 6:93107

[23] Thomson D.M (2005) Matrix models as a tool for understanding invasive plant and native plant interactions Conserv Biol 19:91728

[24] Paul Ongugo Benjamin Owuor and Phesto Osano (2017), Detecting Forest degradation in Kenya: An analysis of hot spots and rehabilitation techniques in Mt. Elgon and Cherangani Hills ecosystems, www.kefriwatertowers.org/.../AFROMONT_Paul\%20Paper22nd\%20Feb\%202017_P. 